\title{
Uterine inversion: a shocking aftermath of mismanaged third stage of labour
}

\author{
Seema Dwivedi, Neena Gupta, Anshu Mishra, Shefali Pande*, Pavika Lal
}

Department of Obstetrics and Gynecology, G.S.V.M. Medical College, Kanpur, India

Received: 29 April 2013

Accepted: 10 May 2013

*Correspondence:

Dr. Shefali Pande,

E-mail: dr.shefali04@gmail.com

(C) 2013 Dwivedi S et al. This is an open-access article distributed under the terms of the Creative Commons Attribution Non-Commercial License, which permits unrestricted non-commercial use, distribution, and reproduction in any medium, provided the original work is properly cited.

\begin{abstract}
Background: To study the incidence, causes, clinical presentations, management and maternal morbidity and mortality associated with acute puerperal inversion of uterus.

Methods: This retrospective study was conducted in Department of Obstetrics and Gynecology, G.S.V.M. Medical College, Kanpur, from March 2008 to March 2013. All the women who developed acute puerperal inversion of uterus either in or outside our hospital were included in the study.

Results: Majority of women presenting with inversion belonged to age group 20-35 years, were multigravida $(68.2 \%)$, came from rural set-up $(81.4 \%)$ and were unbooked $(81.8 \%)$. Majority of deliveries complicated by inversion took place at home $(50 \%)$, delivered by dais $(46 \%)$. Mismanaged 3rd stage of labour proved to be an important factor $(36.4 \%)$ leading to inversion uterus followed by atonicity of uterus. $90 \%$ of women suffered due to delay in management at PHC and $\mathrm{CHC}, 68 \%$ women succumbed to delay in diagnosis at the place of delivery by untrained staff, whereas $45 \%$ women suffered due to delay in transport facility. $13.63 \%$ women suffered from sepsis in post-operative period, $22.72 \%$ from renal failure whereas $18.18 \%$ died.

Conclusion: Proper education and training regarding active management of third stage of labour, diagnosis and management of uterine inversion should be imparted to traditional birth attendants, so that this potentially lifethreatening obstetric emergency could be averted.
\end{abstract}

Keywords: Inversion, Puerperal, Uterus

\section{INTRODUCTION}

Acute puerperal uterine inversion is a rare but potentially life-threatening obstetric emergency in which uterine fundus collapses into uterine cavity. The incidence of uterine inversion varies widely between 1 in 2000 to 1 in 50,000 deliveries, depending mainly on the standards of management of third stage of labour. ${ }^{1}$

Maternal mortality is as high as $15 \% .^{2-4}$ Severe PPH \& shock results from uterine fundus collapsing. Its presentation varies from acute to chronic. Acute uterine inversion occurs within $24 \mathrm{hrs}$ of delivery, subacute between $24 \mathrm{hrs}$ and 4 weeks of delivery and chronic uterine inversion presents after 4 weeks of delivery or in non-pregnant state. ${ }^{5}$ This obstetric complication can cause serious morbidity and mortality, if not promptly recognized or treated. Therefore the cardinal point in its management has to be immediate recognition and prompt treatment.

Various options for treatment of this obstetric emergency which include pharmacological, manual and surgical methods for correcting the inversion have been described in literature.

This study serves to throw light upon the basic tenets of management so as to avert morbidity and mortality at grassroot level with limited access to resources. 


\section{METHODS}

All the women who developed acute puerperal inversion of uterus either in or outside U.I.S.E.M.H. were included in the study.

Women with chronic uterine inversion were not included in the present study.

The protocol followed for management of acute uterine inversion cases were immediate manual replacement. Immediate assistance to be summoned, which includes anesthetist and other physicians.

Adequate large bore intravenous cannulas to be established, crystalloid and blood given to treat hypovolemia. Once anesthesia and tocolysis have been established manual replacement of uterus should be done followed by O'Sullivan's hydrostatic method. The procedure was performed in O.T. with the woman in lithotomy position.

Warm sterile water or isotonic saline is rapidly instilled into the vagina via an i.v. set, while assistant's hand blocks the introitus.

The fluid distends the vagina and pushes the fundus upwards into natural position by hydrostatic pressure. The bag of fluid elevated approximately $100-150 \mathrm{~cm}$ above the level.

Most of the patients could be revived by the manual replacement followed by O'sullivan's method.

\section{RESULTS}

Majority of patients presenting with inversion belonged to age group 20-35 years, were multigravida $(68.2 \%)$, came from rural set-up $(81.4 \%)$ and were unbooked $(81.8 \%)$. Majority of deliveries complicated by inversion took place at home $(50 \%)$, delivered by dais $(46 \%)$ (Table 2). Causes leading to uterine inversion: mismanaged 3rd stage of labour proved to be an important factor $(36.4 \%)$ followed by atonicity of uterus (Table 3). $90 \%$ of patients suffered due to delay in management at PHC and $\mathrm{CHC}, 68 \%$ patients succumbed to delay in diagnosis at the place of delivery by untrained staff, whereas $45 \%$ patients suffered due to delay in transport facility (Table 4).

The condition of the patient at the time of admission: Majority of patients presented with PPH in shock. Shock was initially out of proportion to amount of blood loss (Table 5).

The interventions done for management of inversion. Immediate manual replacement followed by O'sullivans hydrostatic method proved beneficial in majority of cases (Table 6).
Three $(13.63 \%)$ women suffered from sepsis in postoperative period, $22.72 \%$ from renal failure whereas $18.18 \%$ died (Table 7).

Table 1: Demographic profile.

\begin{tabular}{|llll|}
\hline Parameter & Number of & $\begin{array}{l}\text { Nof } \\
\text { patients } \\
\text { patients }\end{array}$ \\
\hline Age & 20-25 years & 7 & $31.8 \%$ \\
\hline & 25-30 years & 8 & $36.4 \%$ \\
\hline 30-35 years & 4 & $18.2 \%$ \\
\hline Parity & Primigravidae & 7 & $13.6 \%$ \\
\hline Socio- & Multigravidae & 15 & $31.8 \%$ \\
\hline economic & Rural & 18 & $68.2 \%$ \\
\hline Admission & Booked & 4 & $81.4 \%$ \\
\hline & Unbooked & 18 & $18.2 \%$ \\
\hline
\end{tabular}

Table 2: Deliveries complicating to uterine inversion.

\begin{tabular}{|llll|}
\hline Parameter & Number of & $\begin{array}{l}\text { \% of } \\
\text { patients }\end{array}$ & patients \\
\hline Delivered at & Home & 11 & $50 \%$ \\
\hline & PHC & 4 & $18 \%$ \\
\hline & CHC & 4 & $18 \%$ \\
\hline Delivered by & Tertiary & 3 & $14 \%$ \\
\hline & Dais & 10 & $46 \%$ \\
\hline & $\begin{array}{l}\text { Midwives } \\
\text { deliveries }\end{array}$ & 8 & $36 \%$ \\
\hline
\end{tabular}

Table 3: Causes leading to uterine inversion.

\begin{tabular}{|lll|}
\hline Parameter & $\begin{array}{l}\text { Number } \\
\text { of patients }\end{array}$ & $\begin{array}{l}\% \text { of } \\
\text { patients }\end{array}$ \\
\hline Atonicity & 4 & $18.2 \%$ \\
\hline Placenta accreta & 4 & $18.2 \%$ \\
\hline $\begin{array}{l}\text { Mismanagement of } 3^{\text {rd }} \\
\text { Stage of labour }\end{array}$ & 8 & $36.4 \%$ \\
\hline Fundal Fibroid & 1 & $4.5 \%$ \\
\hline Precipitate delivery & 2 & $9 \%$ \\
\hline During Caesarean Section & 3 & $13.7 \%$ \\
\hline
\end{tabular}


Table 4: Causes of delay.

\begin{tabular}{|l|c|c|}
\hline Parameter & $\begin{array}{l}\text { Number of } \\
\text { patients }\end{array}$ & $\begin{array}{l}\% \text { of } \\
\text { patients }\end{array}$ \\
\hline Delay in diagnosis & 15 & $68 \%$ \\
\hline $\begin{array}{l}\text { Delay in management at } \\
\text { Primary \& Secondary } \\
\text { Health care }\end{array}$ & 20 & $90 \%$ \\
\hline Delay in transport & 10 & $45 \%$ \\
\hline
\end{tabular}

Table 5: Condition at the time of admission.

\begin{tabular}{|lll|}
\hline Parameter & $\begin{array}{l}\text { Number of } \\
\text { patients }\end{array}$ & $\begin{array}{l}\% \text { of } \\
\text { patients }\end{array}$ \\
\hline Antenatal & 4 & $18.2 \%$ \\
\hline PPH & 8 & $36.4 \%$ \\
\hline Shock - Neurogenic & 4 & $18.2 \%$ \\
\multicolumn{1}{r}{ Haemorrhagic } & 4 & $18.2 \%$ \\
\hline Brought dead & 2 & $9 \%$ \\
\hline
\end{tabular}

Table 6: Interventions done for management of cases.

\begin{tabular}{|lll|}
\hline Parameter & $\begin{array}{l}\text { Number of } \\
\text { patients }\end{array}$ & $\begin{array}{l}\% \text { of } \\
\text { patients }\end{array}$ \\
\hline Johnson's Maneuver & 4 & $36.4 \%$ \\
\hline $\begin{array}{l}\text { Manual replacement } \\
\text { followed by O'sullivan's } \\
\text { method }\end{array}$ & 14 & $45.4 \%$ \\
\hline $\begin{array}{l}\text { Manual replacement } \\
\text { followed by Hysterectomy }\end{array}$ & 4 & $18.2 \%$ \\
\hline
\end{tabular}

Table 7: Outcome in terms of maternal morbidity \& mortality.

\begin{tabular}{|l|l|l|}
\hline Parameter & $\begin{array}{l}\text { Number of } \\
\text { patients }\end{array}$ & $\begin{array}{l}\% \text { of } \\
\text { patients }\end{array}$ \\
\hline Uneventful & 14 & $63.63 \%$ \\
\hline Sepsis in Post-op period & 3 & $13.63 \%$ \\
\hline Renal failure & 5 & $22.72 \%$ \\
\hline Deaths & 4 & $18.18 \%$ \\
\hline
\end{tabular}

\section{DISCUSSION}

Acute puerperal uterine inversion is a rare complication of $3^{\text {rd }}$ stage of labour. It is defined as the turning of the uterus inside out, usually following child birth. The uterine fundus that has inverted and lies within the endometrial cavity without extending beyond the external os is called an incomplete inversion. Complete inversion describes an inverted fundus that extends beyond the external os. ${ }^{6}$ A prolapsed inversion is one in which the inverted uterine fundus extends beyond the vaginal introitus. $^{7}$ A total inversion, usually nonpuerperal and tumor related, results in inversion of the uterus and vaginal wall as well. ${ }^{6}$

Etiology of uterine inversion remains unclear. The most important cause is strong traction on umbilical cord, when the placenta is in fundal location; during the $3^{\text {rd }}$ stage of labour. ${ }^{8}$ In our study also it was a major factor.

Other factors include excessive fundal pressure, relaxed uterus, lower uterine segment and cervix, placenta accreta involving the uterine fundus, short umbilical cord, congenital weakness or anomalies of the uterus and antepartum use of $\mathrm{MgSO} 4$ or oxytocin. ${ }^{9}$

Delay in treatment increases the mortality rate appreciably. Therefore it is essential that a number of measures are taken in a prompt and well co-ordinated manner.

In our study the majority of patients were multiparous, coming from rural set-up. Due to implementation of JSY there was an increase in referral of the patients from remote areas, who could be managed judiciously and expeditiously so as to decrease the morbidity and mortality.

Similarly the majority of inversions took place at home, $\mathrm{PHC}$ or a $\mathrm{CHC}$, often unrecognised and misdiagnosed by untrained dais \& midwives, adding to the agony of patients. Moreover there was delay in transport from the place of delivery to tertiary care centre which further increased the moribund status.

As shown in our study most of the patients landed with intractable PPH and shock by the time they reached a well-equipped centre.

Management of uterine inversion should be step-wise, comprising of non-surgical and surgical approaches.

The first step is summoning appropriate help, followed by resuscitation and stabilisation of the patient. Once the diagnosis has been established, an immediate attempt should be made to replace the uterus manually through the vagina past the cervical ring, with pressure directed upwards towards the umbilicus. This is commonly referred to as Johnson's method. ${ }^{10}$

Should this fail hydrostatic replacement is the next step, as already described. This technique was initially described by O'Sullivan in 1945 and was subsequently modified by Ogueh \& Ayida in 1997, who employed the use of a $6 \mathrm{~cm}$ silastic ventouse cup to correct uterine malposition. ${ }^{11}$ Since then, Antonelli et al. have described a new technique of using a silastic cup at the time of laparotomy. ${ }^{12}$ Use of an intrauterine Rusch balloon 
catheter (Modified hydrostatic method) has also been reported. $^{13}$

Although they were managed by a well-coordinated team approach with obstetrician and anesthetist yet there were some who could not be revived with best resuscitative measures by the time they reached here.

This situation thus demands a very prompt redressal of the problems plagiarizing the basic health care facility.

The untrained dais conducting home deliveries and staff at PHC and $\mathrm{CHC}$ need to be adequately educated about the active management of 3rd stage of labour. It is imperative that they can identify this obstetric emergency so that the patient reaches the tertiary centre well in advance. Also the initial steps like manual replacement and hydrostatic method can be demonstrated so that health care workers can be well trained in carrying out these manoeuvres, thus reducing morbidity and mortality.

Thus these small steps taken at a basic level can prove to be a giant leap in decreasing morbidity and mortality.

\section{CONCLUSION}

Uterine inversion is a catastrophic complication of third stage of labour, if left unrecognized; it will result in severe hemorrhage and shock, leading to maternal death. Manual manipulation should be instituted urgently to reverse the inversion. Tocolytics like magnesium sulfate, terbutaline and halogenated anesthetics can be administered to relax the uterus to aid in reversal. Low dose intravenous nitroglycerin can also be used. O'Sullivan hydrostatic pressure proved to be beneficial as an initial basic life-saving measure. In the most resistant of inversions, surgical correction might be required.

This is especially noteworthy in India as approximately $80 \%$ of deliveries are conducted by untrained birth attendants (Dai's) and they use oxytocic agents injudiciously.

Prevention is better than cure. Uterine inversion is completely preventable with meticulous management of third stage of labour. The morbidity and mortality associated with this complication can be decreased by immediate diagnosis and early initiation of treatment.
We conclude that proper education and training regarding active management of third stage of labour, diagnosis and management of uterine inversion should be imparted to traditional birth attendants, so that this potentially lifethreatening obstetric emergency could either be averted or dealt with more judiciously and expeditiously, if at all it happens. Thus these simple and feasible methods can prove to be a silver lining in the clouded health scenario.

\section{REFERENCES}

1. Hussain $M$, Jabeen $T$, Liaquat $N$, et al. Acute puerperal uterine inversion. J Coll Physicians Surg Pak 2004 Apr;14(4):215-7.

2. Hostetler DR, Bosworth MF. Uterine inversion: a life-threatening obstetric emergency. J Am Board Fam Pract. 2000 Mar-Apr;13(2):120-3.

3. Calder AA. Emergencies in operative obstetrics. Baillieres Best Pract Res Clin Obstet Gynaecol. 2000 Feb;14(1):43-55.

4. Thomson AJ, Greer IA. Non-hemorrhagic obstetric shock. Baillieres Best Pract Res Clin Obstet Gynaecol. 2000 Feb;14(1):19-41.

5. Wendel PJ, Cox SM. Emergent Obstetric management of uterine inversion. Obstet Gynecol Clin North Am. 1995 Jun;22(2):261-74.

6. Salomon CG, Patel SK. Computed tomography of chronic nonpuerperal uterine inversion $\mathrm{J}$ Comput Assist Tomogr 1990;14:1024-6.

7. Lewin JS, Bryan PJ. MR imaging of uterine inversion. J Comput Assist Tomogr 1989;13:357-9.

8. Cunningham FG, MacDonald PC, Gant NF, et al. Williams obstetrics. 20th ed. Stamford, Conn: Appleton \& Lange, 1997:767-9.

9. Shah-Hosseini R, Evrard JR. Puerperal uterine inversion. Obstet Gynecol 1989;73: 567-70.

10. Johnson AB. A new concept in the replacement of the inverted uterus and a report of nine cases. Am J Obstet Gynecol. 1949 Mar;57(3):557-62.

11. Ogueh O, Ayida G. Acute uterine inversion: a new technique of hydrostatic replacement. Br J Obstet Gynaecol 1997;104:951-2.

12. Antonelli E, Irion O, Tolck P, Morales M. Subacute uterine inversion: description of a novel replacement technique using the obstetric ventouse. BJOG. 2006 Jul;113(7):846-7.

13. Uzoma A, Ola B. Complete Uterine Inversion Managed with a Rusch Balloon Catheter. JMC. 2010;1(1):8-9.

DOI: $10.5455 / 2320-1770 . i j \operatorname{rcog} 20130907$

Cite this article as: Dwivedi S, Gupta N, Mishra

A, Pande S, Lal P. Uterine inversion: a shocking aftermath of mismanaged third stage of labour. Int $\mathbf{J}$ Reprod Contracept Obstet Gynecol 2013;2:292-5. 